\title{
AULA-OFICINA: \\ UMA PROPOSTA DE UTILIZAÇÃO DE DOCUMENTOS \\ HISTÓRICOS EM SALA DE AULA
}

\author{
SCHOOL-WORKSHOP: \\ A PROPOSAL FOR USE OF HISTORICAL DOCUMENTS IN CLASSROOM
}

\author{
Ana Paula Anunciação \\ Amábile Sperandio ${ }^{1}$
}

\begin{abstract}
RESUMO: A aula-oficina em questão foi desenvolvida na Escola Estadual Doutor Gabriel Carneiro Martins direcionada para alunos do $7^{\circ}$ ano, tendo como foco a utilização de diferentes documentos históricos na construção do conhecimento histórico, tendo como tema a escravidão negra no Brasil durante o século XVIII. Optamos pelo uso de imagens do pintor francês Jean Baptiste Debret, suas obras são consideradas canônicas no ensino de História, por estarem presentes em todos os livros didaticos de história brasileiro e também por representarem o papel desempenhado pelo escravo negro na sociedade daquele período além de revelar aspectos diversos do cotidiano negro. Utilizou-se também músicas de cantores da cultura popular brasileira tais como Jorge Ben Jor e Clara Nunes, além de vídeos e cantigas relacionadas a capoeira e a cultura negra. A metodologia desenvolvida procurou discutir junto aos alunos diferentes construções históricas acerca do tema, pautada no uso de fontes distintas que direcionam o aluno para o desenvolvimento do pensamento histórico e a sua importância para a vida.
\end{abstract}

Palavras Chave: Aula-oficina. Documentos. Escravidão. Ensino de História. Fontes Históricas.

ABSTRACT: The lecture-workshop in question was developed in the State School Doctor Gabriel Carneiro Martins directed to students of 7th year, focusing on the use of various historical documents in the construction of historical knowledge on the subject of black slavery in Brazil during the eighteenth century. We decided to use images of the French painter Jean Baptiste Debret, his works are considered canonical in the teaching of history, being present in all of history textbooks because they represent the role of the black slave society in that period as well as revealing many aspects of everyday black. Was also used songs from singers of Brazilian popular culture such as Jorge Ben Jor and Clara Nunes, plus videos and songs related to black culture and capoeira. The methodology sought to discuss with students various historical buildings on the topic, based on the use of different sources that direct the student to the development of historical thinking and its importance to life.

Keywords: Lecture-workshop. Documents. Slavery. Teaching History. Historical Sources.

1 Graduandas em História pela Universidade Estadual de Londrina e bolsistas do PIBID/CAPES. 


\section{Introdução}

O presente artigo é resultado de atividades desenvolvidas e inseridas no PIBID (Programa Institucional de Bolsa de Iniciação à Docência) na Universidade Estadual de Londrina. O período em questão na qual as atividades foram estruturadas e aplicadas abrangem desde o início do projeto no mês de junho de 2011 ao mês de abril de 2012 .

O projeto foi desenvolvido como uma proposta diferente ao ensino tradicional de História em sala de aula, tendo como sujeitos ativos no processo de construção do conhecimento histórico alunos do $6^{\circ}$ ano da Escola Estadual Professor Doutor Gabriel Carneiro Martins localizada no bairro Jardim Bancários na cidade de Londrina.

Ao adentrar o universo da sala de aula algumas questões centrais e direcionamentos foram traçados, segundo Maria Auxiliadora Schmidt "a sala de aula não é o espaço onde se transmitem informações, mas o espaço onde se estabelece uma relação em que interlocutores constroem significações e sentidos", sendo assim com base em concepções dinâmicas acerca do ensino de história e sua real função na vida prática e crítica dos alunos foram planejadas aulas-oficinas que ultrapassassem simplesmente um "estudo do passado pelo passado" (SCHMIDT, 2002. p.57.).

O conceito aula-oficina da historiadora Isabel Barca foi essencial para produção de aulas-oficinas estas foram pautadas a partir de competências a serem desenvolvidas nos alunos, as mesmas encontram-se nas principais propostas curriculares para o ensino básico e secundário de História.

Ser competente em História segundo Isabel Barca exige uma compreensão do passado a partir das evidências disponíveis, uma orientação temporal que vise entender as relações entre um passado compreendido, o presente problematizado e o futuro perspectivado (BARCA, 2004 , p. 134). Para que a aula demonstre os resultados positivos almejados é necessário imaginar a aula em concreto com determinada precedência, planejar e explicitar o que deseja ser feito assim contribuindo para a boa execução da aula. 
O modelo pedagógico foi pautado no conceito citado acima, aulaoficina. O mesmo, parte do pressuposto de que os alunos são agentes do seu próprio conhecimento, ou seja, de que o conhecimento é proporcionado através de indagações causadas pelo professor por meio de atividades intelectualmente desafiadoras, porém para que isso seja efetivamente concretizado em sala de aula, Barca afirma que o Professor de história : "Terá que assumir-se como investigador social, aprender a interpretar o mundo conceptual dos seus alunos não para de imediato classificar em certo/errado, completo/incompleto, mas para que esta sua compreensão o ajude a modificar positivamente a conceptualização dos alunos" (BARCA, 2004, p. 133)

O Professor aparece nesse caso não como o detentor do verdadeiro conhecimento, na qual os alunos são apenas ouvintes, mas como investigador social e organizador das atividades que tendem a problematizar o conhecimento histórico, o aluno passa de ouvinte para protagonista da própria aula. Nessa perspectiva de modelo pedagógico o professor auxilia o aluno a desenvolver um pensamento crítico acerca da história, no livro Ensinar História de Maria Auxiliadora Schmidt e Marlene Cainelli, notamos esta relação que deve ser estabelecida entre professor, aluno e o ensino de História:

Ao professor de história cabe ensinar ao aluno como levantar problemas procurando transformar em cada aula de história, temas e problemáticas em narrativas históricas.Ensinar história passa a ser então, dar condições ao aluno poder participar do processo de fazer 0 conhecimento histórico de construí-lo. (SCHMIDT; CAINELLI, 2009, p. 57).

No campo da aprendizagem no âmbito do desenvolvimento da consciência histórica, o aluno ocupa o lugar principal na construção do conhecimento histórico e para alcançá-lo é necessário que primeiramente ele compreenda que a História é formada por teorias, que são aptas a mudanças e ser capaz de entender as diferentes relações presentes nas sociedades. A partir da visão de Rüsen: 
A aprendizagem histórica é um processo de desenvolvimento da consciência histórica no qual deve adquirir competências da memória histórica.As consciências que permitem efetuar uma idéia de organização cronológica que, com coerência interna entre passado, presente e futuro,permitirá organizar a própria experiência de vida, são as mesmas competências que se necessitam para poder receber e também poder produzir historias (RÜSEN ,1992, p. 133)

A relação entre o saber acadêmico e o saber escolar pode ser estabelecida através de pontes conceituais, na obra de Daniel Aarão Reis de 2009, observa-se que o principal objetivo é demonstrar que é possível a utilização da História acadêmica no ambiente da sala de aula. Aarão parte do pressuposto em que há diferença entre história acadêmica, que seria a forma específica e profissional de escrever a história, "metodologicamente controlada", e a História de grande circulação, esta que seria a história que está presente no cotidiano da sociedade e diretamente no cotidiano do aluno:

Enquanto a historia de circulação massiva está mais preocupada em construir uma síntese reduzindo o numero de hipóteses de modo a produzir um passado mais simples e possível de ser amplamente compartilhado, a historia acadêmica, hoje, está mais interessada em multiplicar as hipóteses, ampliando o campo de possibilidades. (REIS, 2009, p. 15)

Ele propõe a utilização da história acadêmica em sala de aula, como a análise de documentos durantes as aulas, e o uso de outros artifícios da história Acadêmica, a qual tem como principal objetivo a construção crítica de um determinado fato. Reis incita um outro ponto, que a história acadêmica ou a escolar seria produzida com o intuito de transmitir o conhecimento histórico, através de uma cultura da escrita e que esta seria para a memorização e entendimento dos fatos históricos:

As formas de transmissão do conhecimento histórico escolar são impregnados de diversas características da cultura da escrita. A fala dos professores em sua exposições, anotações para cópia e leitura, os textos escritos, propostos para leitura, tudo está mergulhado na linguagem escrita que se elabora ao longo do tempo na historia e na escola.Elas funcionam no 
sentido da compreensão e da memorização (na tarefa de rememorar) e esperam o compartilhamento de sentidos por parte de professore e alunos (REIS, 2009, p. 16)

Nessa relação professor e aluno, é interessante que o professor considere os conhecimentos adquiridos pelos alunos fora da sala de aula, ou seja os conhecimentos prévios, e que essa forma ajude o professor a estabelecer um sentido para essa disciplina ,que não seja apenas a titulo de curiosidade.

O uso de fontes históricas nas aulas de História é fundamental para a estruturação do conhecimento histórico, a partir do uso do documento o aluno estabelecerá determinada familiaridade com os eventos passados do período em questão auxiliando no desenvolvimento do raciocínio histórico. O trabalho com fontes históricas pode ser o ponto de partida do ensino de História, porém exige determinado cuidado e conhecimento para que o uso dos documentos não seja em vão. No ensino de História , a utilização de documentos fez com que o ensino se tornasse mais amplo e dinâmico deixando de lado o caráter livresco. Neste caso, com base na obra de Schmidt e Cainelli:

\footnotetext{
Nessa perspectiva, os documentos não serão tratados como fim em si mesmos, mas deverão responder as indagações e as problematizações de alunos e professores, com o objetivo de estabelecer um diálogo com o passado e o presente, tendo como referência o conteúdo histórico a ser ensinado." (SCHMIDT; CAINELLI, 2009, p. 117)
}

O professor deve ampliar suas concepções acerca do uso e do próprio documento em si, o tipo de documento histórico trabalhado traçando assim os objetivos que se deseja alcançar na utilização das diversas fontes, sejam elas iconográficas, escritas, sonoras.

Em contrapartida o aluno deve explorar de diversas formas as informações contidas nos documentos que lhe está sendo apresentado e na junção dos conhecimentos que traz consigo do assunto aumentando assim suas argumentações históricas.

O desenvolvimento das aulas-oficinas foi composto de dois momentos a elaboração e aplicação do projeto piloto em determinada turma de alunos 
do colégio no caso a 70 Ano B durante os meses de novembro e dezembro de 2011 e o segundo momento com modificações no projeto piloto inicial no 70 ano D no mês de abril de 2012.

O tema principal das aulas-oficinas foi a Escravidão negra no Brasil durante a primeira metade do século XIX. Em terras brasileiras a escravidão aconteceu primeiramente nos engenhos a partir do século XVI, pois os trabalhos nas plantações de cana de açúcar exigiam grande número de mão de obra e a tentativa de escravizar os índios não foi bem sucedida, pois faziam parte de uma cultura na qual estavam acostumados com uma vida livre e cujo os trabalhos mais densos eram realizados pelas mulheres, neste âmbito os índios não se adaptaram ao trabalho pesado das lavouras e tinham melhores condições para a resistência do que os escravos africanos:

Os índios resistiram às várias formas de sujeição, pela guerra, pela fuga, pela recusa ao trabalho compulsório. Em termos comparativos, as populações indígenas tinham melhores condições de resistir do que os escravos africanos. Enquanto estes se viam diante de um território desconhecido onde eram implantados à força, os índios se encontravam em sua casa. (FAUSTO, 1999, p. 23)

O sistema escravista era desenvolvido em terras africanas em que consistia na venda de inimigos que se transformavam em escravos para reinos diferentes ou até mesmo para territórios árabes, a chegada dos europeus só reafirmou um sistema que já existia no continente africano. A partir de 1441, os portugueses começaram a escravizar os negros,estes eram levados para Portugal e eram utilizados em trabalhos domésticos e urbanos.No Brasil, os portugueses recorreram a utilização da mão de obra escrava pois:

[...] colonizadores tinham conhecimento das habilidades dos negros, sobretudo por sua rentável utilização na atividade açucareira das ilhas do Atlântico. Muitos escravos provinham de culturas em que trabalhos com ferro e a criação de gado eram usuais. Sua capacidade produtiva era assim bem superior à do indígena. (FAUSTO, 1999, p. 24) 
A partir do tema foi estabelecido um recorte cultural utilizando diferentes fontes: iconográficas, músicas, cantigas populares e vídeos relacionados ao assunto. Abrangendo o tema escravidão através do recorte estabelecido desenvolveu-se a questão do negro em seu tempo através de imagens do pintor Jean Baptiste Debret.

Segundo Valéria Lima (2004), o pintor nasceu no ano de 1768, em Paris, França advindo de uma família que possuía posições sociais reconhecidas, por exemplo, seu pai, Jacques Debret, era tabelião,funcionário do rei,dedicava-se aos estudos de História Natural, ou seja, faziam parte da culta burguesia do período, teve sua formação intelectual profunda sendo esta desenvolvida em um meio político conturbado da França revolucionária. Tornou-se um dos principais nomes de sua época sendo considerado por muitos o mais competente no que desejava revelar por meio de sua arte. Debret veio ao Brasil a serviço oficial da corte portuguesa, sendo um dos membros da Missão Artística Francesa²; por meio desta acreditava-se que uma cultura erudita alcançaria as terras brasileiras revolucionando o panorama de Belas- Artes e inserindo o sistema superior acadêmico.

Valéria Lima (2004) em sua obra afirma que o pintor era responsável por retratar momentos da família real e acontecimentos importantes que envolvessem os membros da corte como o funeral da rainha D. Maria I; porém após estar no Brasil o artista ampliou o caráter de suas obras, Debret procurou resgatar particularidades do país e do povo abordando os diferentes contextos culturais e sociais da época, o artista desejava mostrar um Brasil que merecesse ocupar um lugar junto a marcha da civilização assim tornando-se referência nas artes.

\footnotetext{
${ }^{2}$ Segundo Lúcia Maria Bastos Pereira das Neves: no dia 26 do fevereiro, a Missão Artística Francesa chegou ao Rio de Janeiro, do navio Calphe, vindo do porto do Havre de Grâce, trazendo a bordo vários franceses, artistas de profissão, para residir naquela que era então a sede da monarquia portuguesa. Essa proposta vinha no bojo das transformações ocorridas no Brasil, em especial, no Rio de Janeiro, com a transferência da Família Real portuguesa, quando surgiu a necessidade básica de formar uma sociedade culta e ilustrada ao redor da nova Corte, além de aperfeiçoar o aparelho central da Coroa portuguesa em terras americanas, despertando a antiga colônia para uma modernização segundo padrões europeus. Disponível em http://bndigital.bn.br/redememoria/missfrancesa.html
} 
Em seu número de 6 de abril de 1816, a Gazeta do Rio de Janeiro, periódico considerado como porta-voz do governo, noticiou a chegada à cidade, no dia 26 do mês anterior, do navio Calphe, vindo do porto do Havre de Grâce, trazendo a bordo vários franceses, artistas de profissão, para residir naquela que era então a sede da monarquia portuguesa.

As imagens do pintor francês são consideradas por muitos autores da historiografia como canônicas no ensino de história, facilmente encontramos suas imagens em livros didáticos quando o tema é relacionado à História do Brasil, compreendemos que ícones canônicos:

(...) seriam aquelas imagens-padrão ligadas a conceitos-chave de nossa vida social e intelectual. Tais imagens constituem pontos de referência inconscientes, sendo, portanto, decisivas em seus efeitos subliminares de identificação coletiva. São imagens de tal forma incorporadas em nosso imaginário coletivo que as identificamos rapidamente. Todos nós lidamos, a todo momentos, com imagens canônicas. (SALIBA apud CAPELLATO, 2005, p. 88)

Jean Baptiste Debret deixou grande herança iconográfica do tempo dos escravos através de seus quadros, as imagens relatam situações vividas pelos escravos, tais como: torturas, trabalhos geralmente exercido por eles na época, rituais religiosos dentre outras atividades e costumes.

Abrangendo o recorte histórico cultural estabelecido, a Capoeira enquanto resistência foi utilizada para retratar a realidade e experiência negra da época considerando esta como atividade cultural afrodescendente presente até os dias atuais.

Segundo Carlos Eugênio Líbano Soares (2004), a Capoeira surgiu em meio a repressão e tortura sofrida pelos escravos por volta de 1600, porém não se sabe ao certo se o local de origem foram as senzalas ou os quilombos. Praticavam nas senzalas nos momentos de folga aliando golpes, a ginga e a música para que os senhores não desconfiassem que na realidade a dança possuía um caráter de luta e defesa, os golpes eram inspirados nos movimentos dos animais africanos e brasileiros.

Durante a fuga para os quilombos, a Capoeira foi de suma importância para a resistência contra os capitães do mato e capatazes pois 
os escravos não possuíam armas somente o corpo para se defender e mesmo sem armas não foram submetidos a escravidão sem se revoltarem,os negros se escondiam nas matas e assim que ameaçados utilizavam os golpes para atacar seus inimigos em busca da liberdade, esta que estava enraizada em todo negro que foi submetido a escravidão no Brasil.Segundo Boris Fausto:

Seria errôneo pensar que, enquanto os índios se opuseram à escravidão, os negros a aceitaram passivamente. Fugas individuais ou em massa, agressões contra senhores, resistência cotidiana fizeram parte das relações entre senhores e escravos, desde os primeiros tempos. Os quilombos, ou seja, estabelecimentos de negros que escapavam à escravidão pela fuga e recompunham no Brasil formas de organização social semelhantes às africanas, existiram às centenas no Brasil colonial. (FAUSTO, 1999)

Foram estabelecidos dois momentos para a aplicação da aula oficina o projeto piloto e o projeto definitivo.

\section{Projeto piloto}

O projeto piloto foi dividido em 3 aulas-oficinas que se completassem entre si. Na primeira aula-oficina desenvolvida a fonte histórica principal foi a obra do pintor Debret, porém antes de aprofundar a discussão histórica sobre o artista e sua representação da escravidão a questão das fontes históricas e sua importância foram trabalhadas junto aos alunos revelando o papel fundamental que o uso de documentos históricos exercem no ensino de História, foram escolhidas 6 pinturas que revelassem realidades diferentes do universo negro e a partir da análise da obra os alunos foram direcionados a uma investigação histórica acerca dos elementos presentes em cada imagem. Abaixo segue as imagens utilizadas e os seguintes questionamentos levantados acerca das imagens com os alunos

A partir da tela 1, vários elementos podem ser destacados como a presença do café, os simbolismos culturais encontrados nas vestimentas 
dos escravos, o porta-bandeira, o animador os escravos trabalhando no transporte de sacos de café.

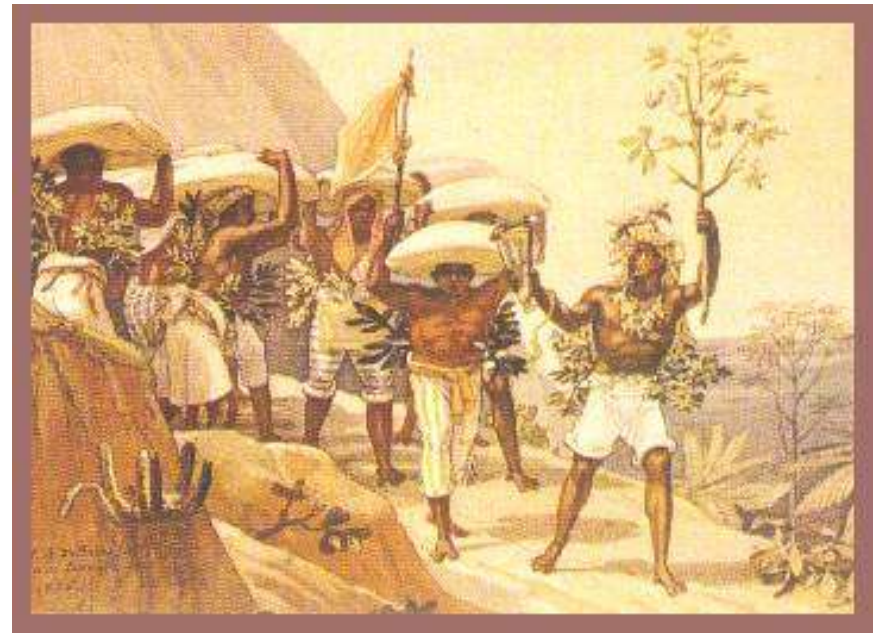

Tela 1 - Comboio de café seguindo para a cidade (DEBRET, 1827) 3

A tela 2 representa o batismo em crianças negras, o mesmo era considerado bárbaro pelas condições em que a criança era submetida ao ser batizada. O padre negro na imagem representa a forte religiosidade do período e sua importância para a sociedade.

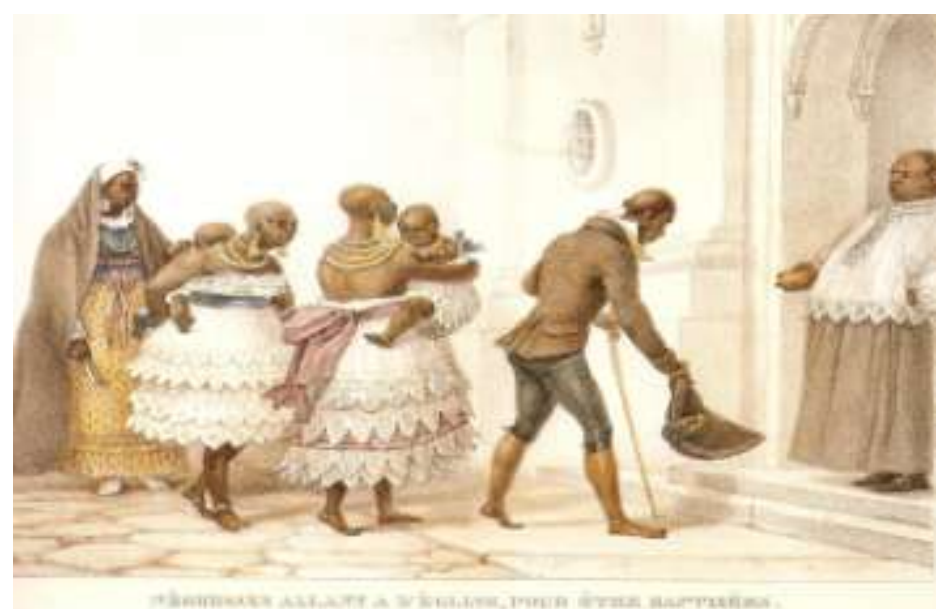

Tela 2 - Jovens negras indo à igreja para serem batizadas (DEBRET1821)

3 Todas as imagens foram retiradas de DEBRET, Jean B. Viagem pitoresca e histórica ao Brasil. São Paulo: Martins;Brasília: INL, 1975 
$\mathrm{Na}$ imagem abaixo identificamos uma das atividades que tinham destaque na época, as fábricas de sapato; a partir da tela pode ser notado o trabalho escravo nas mesmas e até mesmo as punições, neste caso através da palmatória.

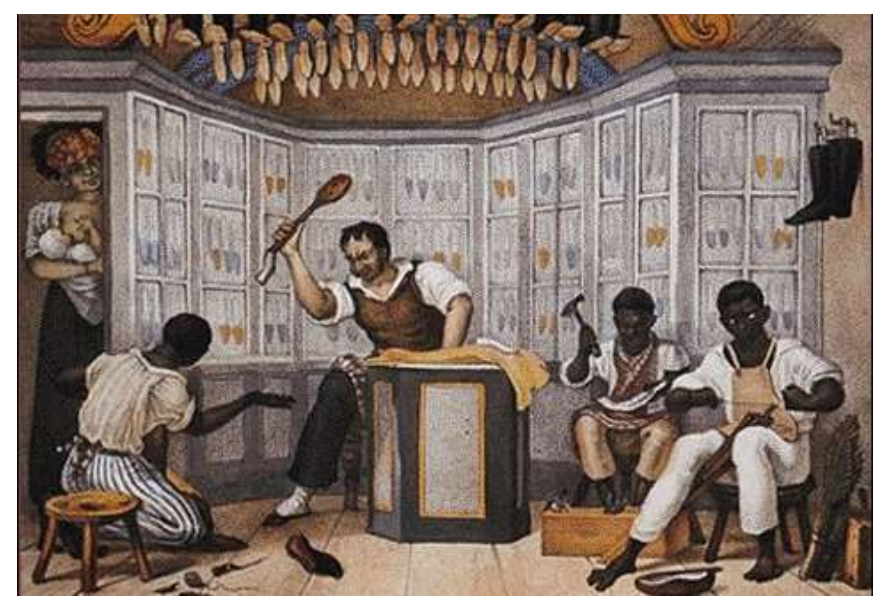

Tela 3 - Sapataria (DEBRET-1835)

No uso da imagem abaixo é possível que o aluno conheça outros aspectos sobre a escravidão, o universo dos curandeiros que trabalhavam nas ruas curando escravos feridos em torturas e atendendo os mais necessitados, neste caso o negro trazia consigo conhecimentos da medicina popular da África integrados a sua cultura.

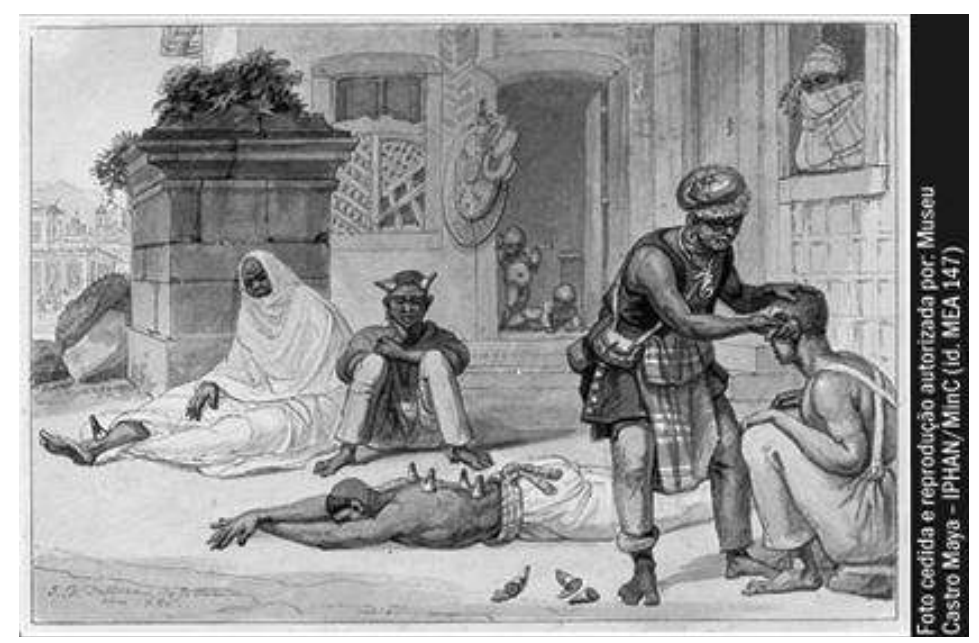

Tela 4 - O Cirurgião Negro (DEBRET-1835) 
A imagem que segue é rica em elementos para ser analisados, interrogados e discutidos. O castigo pesado em que o escravo está submetido sobre as mãos do feitor branco que na maioria das vezes era português. A postura corporal a dor e o sofrimento. Ao fundo da imagem nota-se escravos observando e trabalhando na lavoura.

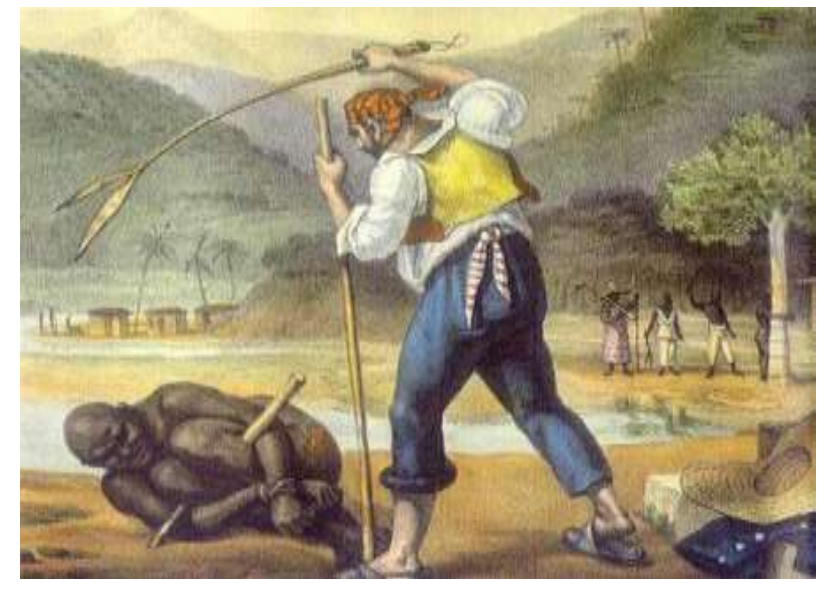

Tela 5 - Feitores Castigando Negros (DEBRET-1835)

Esta imagem da tela 6 a seguir é considerada uma das mais clássicas e conhecidas do pintor, na atividade executada encontramos certo entusiasmo dos alunos ao descrevê-la. A cena abaixo representa uma tortura sofrida em praça pública, na qual os escravos que haviam cometido faltas consideradas graves recebiam. O clima de tensão do momento é transmitido através da pintura, os escravos feridos ao chão, os que observam enquanto os companheiros recebem açoites com chicotes de couro ressecado. 


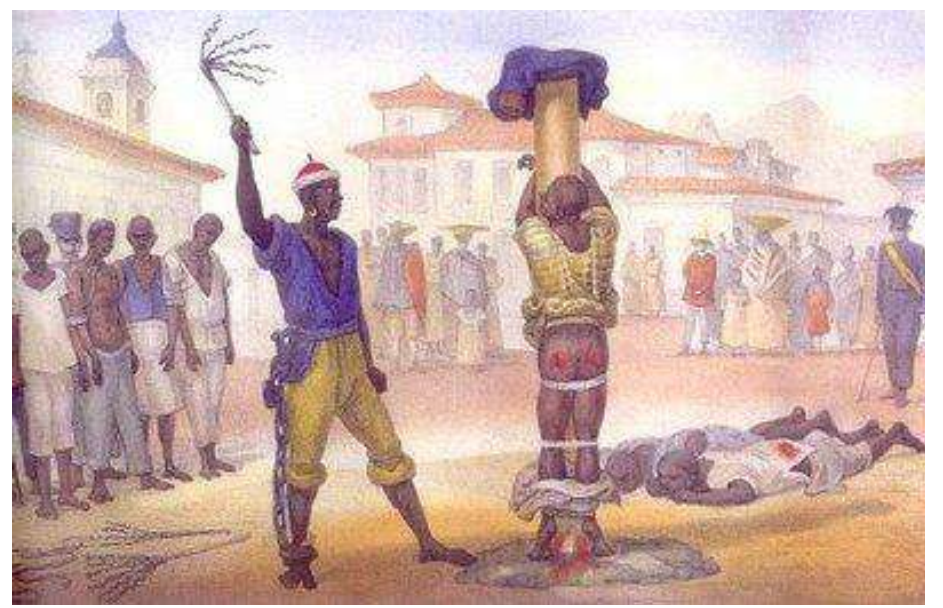

Tela 6 - Execução do Castigo de Açoite (DEBRET-1835)

O trabalho com as imagens junto aos alunos esteve pautado em um caráter investigativo, na qual os alunos deveriam indagar as imagens uma a uma, sobre o máximo de elementos distintos que é possível encontrar em tais e a partir dessa atividade investigativa deveriam associar ao cotidiano negro e o que as imagens podem relatar sobre o período, qual a visão do pintor e os aspectos da obra e da época em que foi produzida.

Após trabalhar com a escravidão a partir das imagens, trabalhou-se no projeto piloto a música do grupo de rap Z'África Brasil- Antigamente Quilombos,Hoje Periferia (Letra Anexo 1) a música apresenta o negro na sociedade atual, o preconceito presente ainda hoje e as feridas deixadas pela Escravidão.

A música Zumbi (Letra Anexo 2) do músico e compositor Jorge Ben Jor também foi trabalhada na aula-oficina, a música está intimamente ligada a Escravidão e a cultura negra, a letra da música inicia citando várias localidades de origem dos negros que foram trazidos para o Brasil, ligandoos de certa forma a sua terra ancestral - os reinos negros da África. A música também fala sobre Zumbi e o tipo de trabalho exercido por mãos negras na época da escravidão, a música apresenta instrumentos da cultura africana como atabaque e cuíca.

Por meio da interpretação de obras selecionadas que direcionaram os alunos ao universo escravo do período e o cotidiano vivido e as diferentes atividades realizadas naquela época e também a partir das músicas 
analisadas os alunos desenvolveram um raciocínio histórico acerca da escravidão e as mazelas tais como preconceito racial e social.

A primeira atividade realizada no projeto piloto, os alunos deveriam desenhar sobre a escravidão com base nos aspectos encontrados nas obras analisadas de Debret e nas letras das músicas discutidas. No gráfico abaixo segue uma tabulação dos principais temas encontrados nos desenhos do projeto piloto, da primeira turma que participou da aula oficina. No total foram obtidos 12 desenhos, os mesmos apresentavam certa identificação histórica entre os temas retratados sendo possível realizar uma tabulação com base nas concepções relacionadas as competências históricas de Isabel Barca nos desenhos.

$\square$ Questões de identidade racial
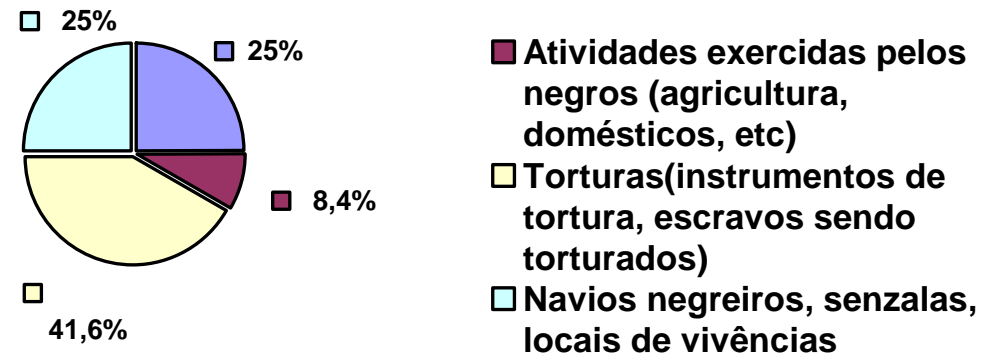

\section{Gráfico 01: Temas mais apresentados sobre escravidão. Total de 12 alunos}

Alguns dos desenhos ilustrados pelos alunos que caracterizam os temas: 


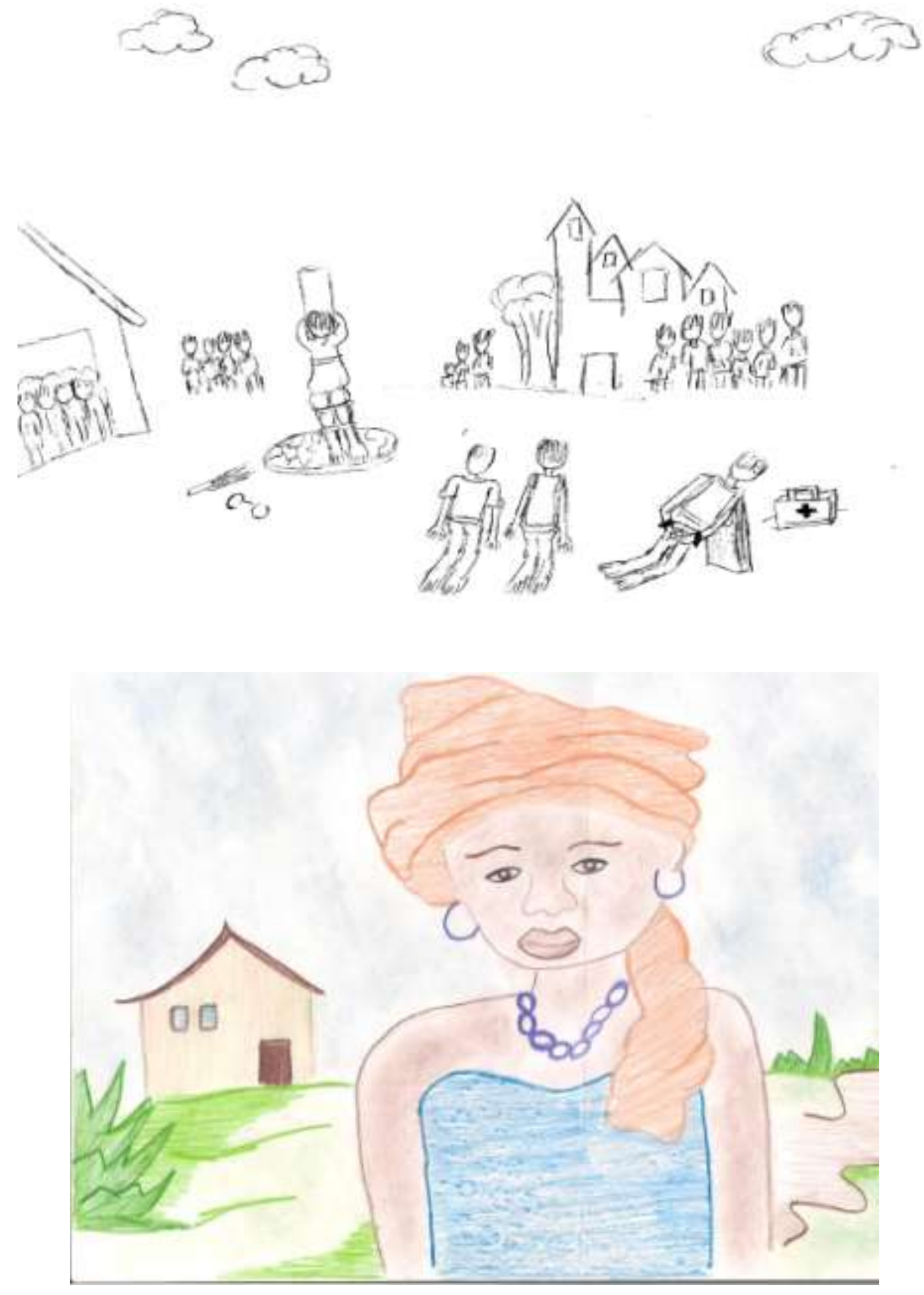

Nas imagens acima detectamos uma das competências em história que Isabel Barca sugere em seu texto Aula Oficina: Do projeto à avaliação (Pág 131-144); nele a autora as sintetiza em subdivisões sendo elas: Interpretação de fontes; Compreensão contextualizada, Comunicação. Nos desenhos representados a competência que está presente é a que se refere à Interpretação de fontes, pois notamos nos mesmos a presença da obra de Debret e a questão da identidade racial discutida na música, neste 
âmbito foi detectada a relação estabelecida pelos alunos entre as diferentes fontes trabalhadas

Na segunda aula-oficina do projeto piloto, o tema principal foi a capoeira. As fontes estabelecidas para trabalhar com os alunos foram vídeos de mestres contendo depoimentos sobre o seu surgimento, experiências de vida e significados que envolvem essa manifestação cultural herdada dos escravos ; cantigas populares da capoeira também foram usadas como fonte histórica e a importância dos elementos apresentados nas letras das cantigas que remetem ao dilema vividos pelos negros durante a escravidão.

Após os alunos estabelecerem um contato com as cantigas, com os instrumentos da capoeira e seus respectivos significados simbólicos e culturais, foi desenvolvida uma atividade em grupo na qual os alunos eram responsáveis por criar suas próprias cantigas de capoeira. Com base em conceitos chaves identificados nas cantigas produzidas foi possível traçar uma tabulação referente aos conceitos que compõem a aprendizagem histórica dos alunos em relação ao tema. No total foram 6 grupos compostos por $4 a 5$ alunos que compuseram as cantigas, tomamos como base o número de vezes em que foram utilizados um ou mais conceitos presentes nas letras que remetem a escravidão, portanto houve grupos que se enquadraram em mais de classificação abaixo

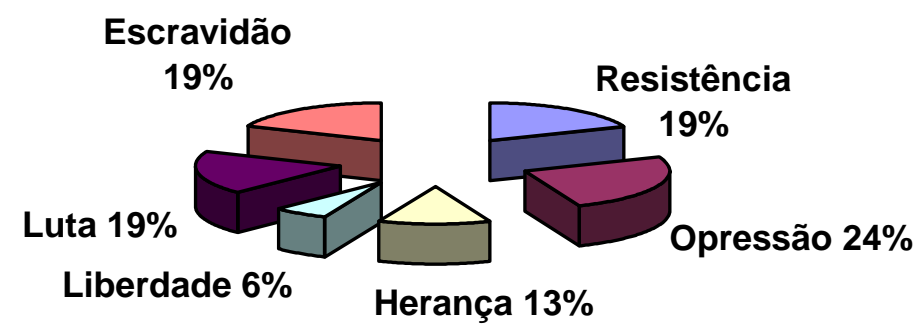

\section{Gráfico 2 - Conceitos-chaves encontrados nas cantigas produzidas na aula-oficina. Total de alunos que encontraram: 16}


Portanto, a partir da tabulação foi possível notar que os alunos conseguiram estabelecer certa relação entre as fontes que haviam sido trabalhadas, os conhecimentos prévios, pois ao aparecer a palavra herança mais de uma vez, demonstram a relação passado-presente que desenvolveram durante a aprendizagem histórica. No projeto piloto alguns elementos utilizados foram questionados acerca do resultado proposto e obtido, sendo assim para a produção do projeto definitivo ocorreram mudanças no uso de determinadas fontes.

\section{Projeto definitivo}

Com base no projeto piloto e seus resultados, o projeto definitivo foi estruturado de acordo com as mudanças estabelecidas e desenvolvido durante o mês de abril de 2012.

A primeira modificação foi no uso da música Z'África BrasilAntigamente Quilombos, Hoje Periferia; a música apresenta uma letra crítica porém por ser extensa fez com que os alunos perdessem o interesse em analisá-la sendo a música voltada para um público mais velho de acordo com o vocabulário nela presente, porém a opinião a respeito do uso da mesma só foi construída a partir da experiência em sala de aula.

A substituição foi feita pela música Canto das Três Raças (Letra Anexo 3) da intérprete Clara Nunes; a escolha da música foi feita a partir do que se desejava discutir, a construção da identidade brasileira, os povos que contribuíram para formação do povo brasileiro, sendo um deles o o africano; a música estabeleceu uma ligação com as outras fontes utilizadas e os alunos demonstraram grande interesse pelo uso e análise da mesma.

Devido as condições inadequadas dos materiais áudio-visuais dispostos pela escola, no caso a TV Pendrive, os vídeos usados no projeto piloto foram retirados do projeto definitivo, pois houve certa dificuldade das crianças em compreender as falas dos personagens.

As fontes históricas que permaneceram foram: as imagens do pintor Debret, a música Zumbi- Jorge Ben Jor e as cantigas populares de capoeira. 
As atividades propostas no projeto piloto permaneceram no projeto definitivo revelando os aspectos diferentes de cada turma e acentuando a peculiaridade e particularidade das mesmas.

Abaixo segue duas imagens do projeto definitivo que representam a primeira atividade realizada pelos alunos, na qual eles deveriam desenhar acerca da escravidão.
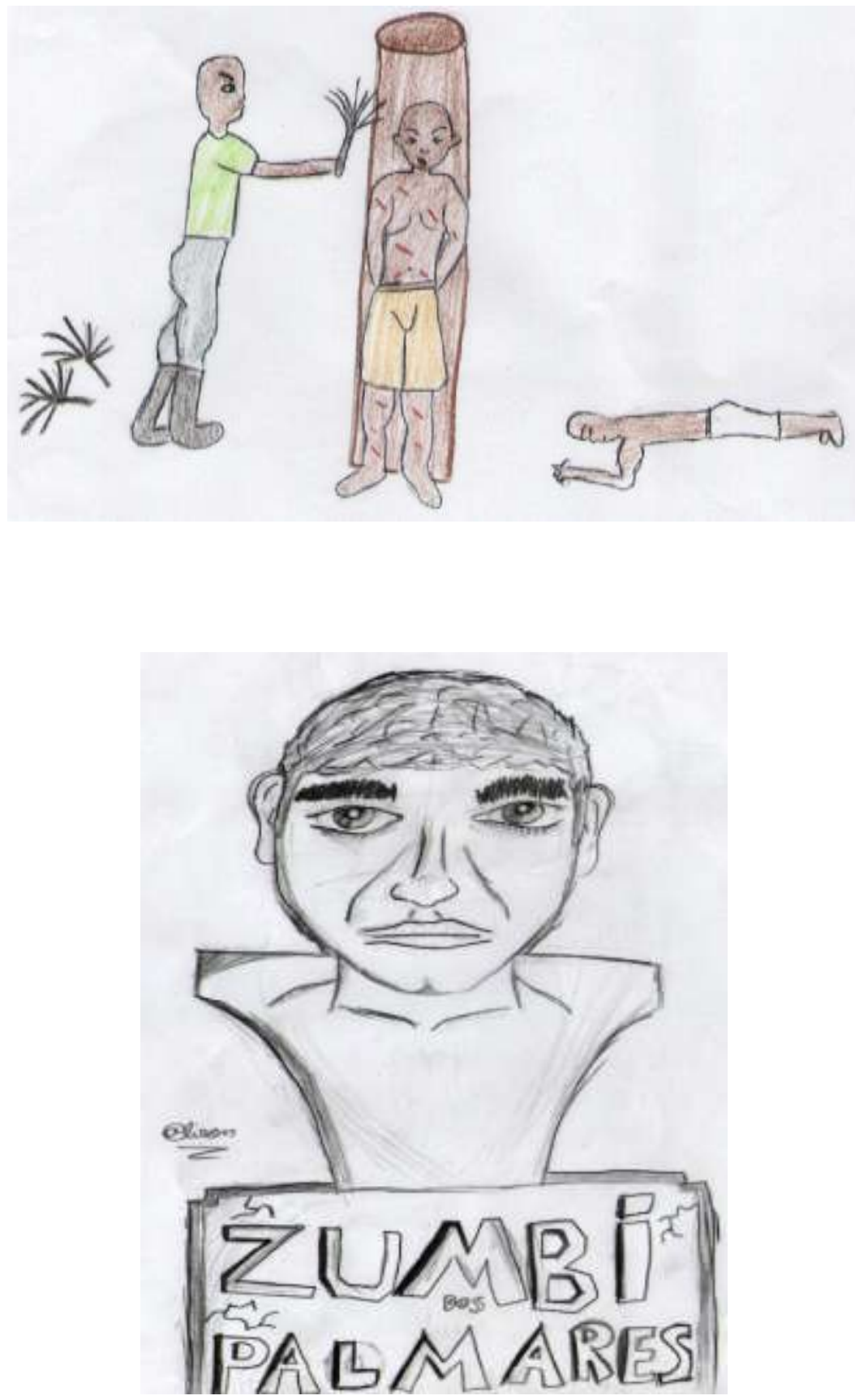

Desenhos produzidos pelos alunos do 70 ano $\mathrm{C}$ da Escola Estadual Professor Doutor Gabriel Carneiro Martins - Projeto Definitivo.

História \& Ensino, Londrina, v. 18, p. 131-156, Especial, 2012 


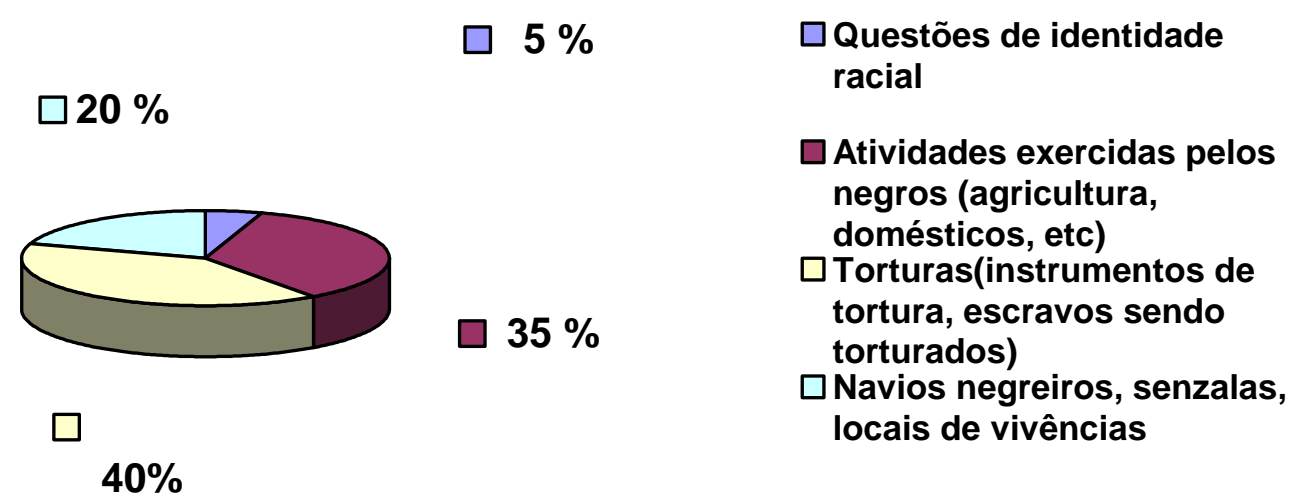

Gráfico 3 - Temas mais apresentados sobre escravidão no total de 20 alunos

As cantigas desenvolvidas no projeto definitivo apresentaram certa identificação em conceitos-chaves utilizados assim como no projeto piloto. A partir do mesmo foi possível tabular da mesma maneira no projeto definitivo.

No mesmo formato do projeto piloto, a turma se dividiu em 4 grupos e realizaram a produção das cantigas,

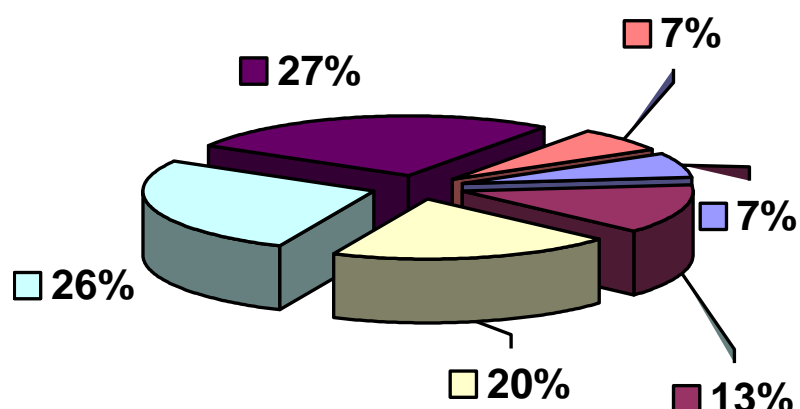

\begin{tabular}{|l|}
\hline Resistência \\
$\square$ Opressão \\
$\square$ Herança \\
$\square$ Liberdade \\
$\square$ Luta \\
$\square$ Escravidão
\end{tabular}

\section{Gráfico 4 - Conceitos-chaves encontrados nas cantigas produzidas nas na aula-oficina. Total de vezes que se apresentaram: 16}


Os gráficos revelam quais foram os conceitos e temas que guiaram a aprendizagem histórica dos alunos. Nos desenhos feitos na primeira atividade tanto no projeto piloto quanto no projeto definitivo, notamos uma grande quantidade de desenhos relacionados a tortura sofrida pelos escravos, as mesmas também retratadas nas obras de Debret. Notamos o cruzamento de fontes realizadas pelas crianças e as possíveis ligações estabelecidas entre elas, além de percebermos por meio das atividades o que foi associado e absorvido do tema pelos alunos.

O segundo tema em destaque está relacionado ao trabalho executado pelos escravos na época, presente em grande parte dos desenhos em ambos os projetos, os alunos retrataram as diversas atividades tais como na área da agricultura, doméstica e trabalhos no comércio. Os outros temas representados se equilibram nos desenhos produzidos tanto no projeto piloto quanto no projeto definitivo.

$\mathrm{Na}$ produção das cantigas de capoeira no projeto piloto os conceitos chaves que ganham destaque em ordem: Escravidão, resistência, opressão e luta seguidos por herança e liberdade. Já no projeto definitivo os que aparecem em destaque em ordem são: liberdade, luta, herança, seguidos por opressão, resistência, escravidão. Abaixo segue um dos exemplos de cantigas escritas na aula oficina.

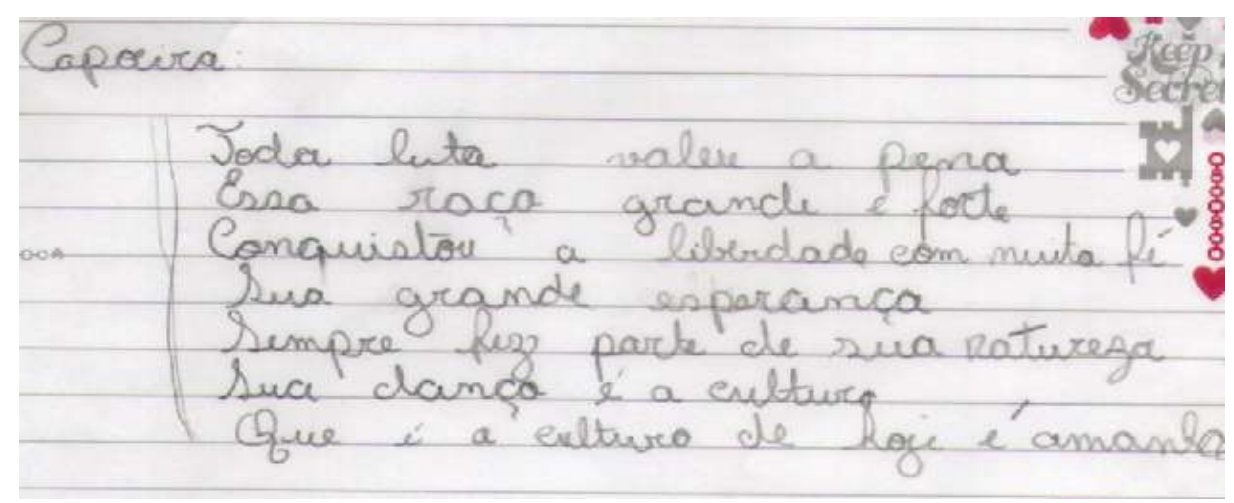




\section{Considerações Finais}

O desenvolvimento do artigo teve como fundamento relatar e discutir a experiência vivida em sala de aula com base em autores conceituados no campo da Educação Histórica, como Isabel Barca, Maria Auxiliadora Schmidt, Marlene Cainelli.

A partir da execução da aula-oficina a dinâmica do ensino de História se fez presente, ao explorar fontes diversas levando em consideração os conhecimentos prévios dos alunos que se faz essencial numa prática de aula oficina, foi possível notar diferentes aspectos que se referem a competências essenciais relacionadas ao conhecimento histórico. O ser competente em história, segundo Barca (2004) requer:

... uma compreensão contextualizada do passado, com base na evidência disponível, e pelo desenvolvimento de uma orientação temporal que se traduza na interiorização de relações entre 0 passado compreendido, 0 presente problematizado e o futuro perspectivado. (BARCA, 2004, p. 134)

As competências históricas de Barca,estiveram inseridas em todo processo de aprendizagem dos alunos. A relação dinâmica entre professoraluno foi primordial para que os objetivos fossem alcançados, sendo um dos principais auxiliares do aluno na construção de um conhecimento em que ele é sujeito ativo em todo o processo a partir de uma visão crítica do ensino de História e da própria sociedade em que faz parte.

Concluímos que os alunos foram capazes de participar ativamente sendo os protagonistas da própria aula-oficina, interpretaram fontes variadas, compreenderam o contexto na qual estavam inseridas, suas intenções, levantaram questões acerca do contexto histórico da qual faziam parte e conseguiram expressar o conhecimento adquirido com inteligência e sensibilidade por meio das atividades realizadas.

As aulas-oficinas proporcionaram de certa forma um amplo leque de questões a serem discutidas, como por exemplo, o ensino de história, sua função e desenvolvimento em sala de aula e a possibilidade de ultrapassar 
as barreiras de um ensino tradicional optando por métodos dinâmicos e recortes diferentes relacionados a um mesmo tema.

\section{Referências Bibliográficas}

ALENCASTRO, L. F. O Trato dos Viventes. Formação do Brasil no Atlântico Sul. São Paulo: Cia das Letras, 2000.

BARCA, I. Aula Oficina: do Projeto à Avaliação. In. BARCA, I. (Org.) Para uma educação de qualidade: Atas da Quarta Jornada de Educação Histórica. Braga, Centro de Investigação em Educação (CIED)/ Instituto de Educação e Psicologia, Universidade do Minho, 2004, p. 131 - 144.

CAPELATO, M. H. et al. História e Cinema: dimensões históricas do audiovisual. São Paulo: Alameda, 2007.

DEBRET, J. B. Viagem pitoresca e histórica ao Brasil. São Paulo: Martins. Brasília: INL, 1975

FAUSTO, B. História Geral do Brasil. São Paulo: Edusp, 2000.

LIMA, V. Uma Viagem com Debret. RJ: Ed. Jorge Zahar, 2004.

PRADO, J. F. A. O artista Debret e o Brasil. São Paulo: Nacional, 1990. (Col. Brasiliana), v. 386.

REIS, D. A. Apresentação. In: ROCHA, H. A. B.; MAGALHÃES, M. de S.; GONTIJO, R. A escrita da história escolar: memória e historiografia. Rio de Janeiro: FGV, 2009.

SCHMIDT, M. A. A formação do professor de História e o cotidiano da sala de aula. In: BITTENCOURT, C. (Org.). O saber histórico na sala de aula. São Paulo: Contexto, 2002.

Unijuí, 2011.

; CAINELLI, M. (Org.). Educação histórica: Teoria e pesquisa, Ijuí:

; CAINELLI, M.; Ensinar História. Pensamento e ação na sala de aula. 2 ed.- São Paulo: Scipione, 2009.

SOARES, Carlos Eugênio Líbano. A negregada instituição: os capoeiras na corte imperial (1850-1890). São Paulo: Unicamp, 2004.

\section{Músicas:}

Z'África Brasil - Antigamente Quilombos, Hoje Periferia ,2002. Álbum: Antigamente Quilombos, Hoje Periferia. Anexo 1 
Zumbi - Composição letra e música Jorge Bem Jor -1972, Álbum: "A Tábua de Esmeralda - 1972". Anexo

CANTO DAS TRÊS RAÇAS - Clara Nunes Composição: Mauro Duarte e Paulo César Pinheiro 1974. Anexo3

\section{Anexos:}

\section{Anexo 1: \\ Antigamente Quilombo Hoje Periferia Zafrica Brasil}

\section{REFRÃO:}

A que sentido flores prometeram um mundo novo?

Favela viela morro tem de tudo um pouco,

Tentam alterar o DNA da maioria.

Rei Zumbi! Antigamente Quilombos Hoje Periferia!

Levante as caravelas aqui nâo daremos tréguas nâo, nâo

Entâo que venha a guerra

Zulu Z'Africa Zumbi aqui nâo daremos trèguas nâo, nâo

Entâo que venha a guerra

Sempre a mil aquì Z'Africa Brasil

Pra quem fingiu que não viu a cultura resistiu

Num faroeste de caboclos revolucionários

È o Z Zumbi que Zumbazido Zuabido Zumbizado

A lei da rua quem faz è você no proceder

Querer è poder, atitude è viver

Hoje centuplicarei o meu valor

Eliminando a dor que afeta o meu interior

Querem nos destruir mas nâo vâo conseguir

Se aumentam a dosagem mas iremos resistir

Evoluir não se iludir com inimigo

Que transforma cidadão em bandido, perito em latrocínio.

Os hereditários sempre tiveram seus planos

Ao lado de uma par de dólar furado e falso e se encantam

È cadeira de balanço ou è cadeira elétrica

Gatilhos tiros na favela e o sangue escorre na viela

Um dia sonhei que um campinho da quebrada era uma fábrica da Taurus

Ainda bem que era um sonho e aì fiquei um pouco aliviado

Mas algo em meu pensamento dizia pra mim

Porra! Se na periferia ninguém fabrica arma

quem abastece isso aqui?

O sistema não está do lado da maioria

Já estive por aquì sei lá quantas vidas e continua a covardia,

Esquenta não, somos madeira que cupim não rói, a gente supera 
todas as drogas e as armas que estão aquì devolveremos em guerra!

REFRÃO

Mundo abominado desorientado não seja um mini-game manipulado

Iguinorando a ação do sistema, mas por outro lado

Faça sua Taboca, levante sua Paliçada

Prepare-se.. não acredite em contos de fardas

A fumaça è o veneno que destrói as flores

A visão do mundo em diversos fatores subjulgado à valores

Consomem a essência em troca a sobrevivência

Assim espalham a doença, a fé,e a crença

E o povo lamenta tantos destroços tanta perda

Fio de quinhentos volts em muitas conciências.

Vejam: úlcera de ozônio, pânico da atmosfera

As coisas não estão nada bela, SOS planeta terra

Acredite à milhões de anos o poder impera, o oprimido resiste

e o opressor insisti na guerra,

Refúgio. Ver nuvem negra brilhar sistema o alvo certeiro

O mal aplicado diante de princípios morais lamentos, levantamentos

Históricos monumentos

Carne e osso meu corpo não è blindado seu peito

Biografia plano real

Agora nos encontramos mau excelentíssimo senhor presidente

do território nacional

Do sistema escudo, guerrilheiros do mundo duque 13 blefou

Zumbi,o redentor, agora o jogo virou,quilombos guerreou, periferia acordou

Cansamos de promessas, volta pro mato capitão

pois ja estamos em guerra!!

REFRÃO

Medito a ação, hino da redenção

Os deuses encorajaram as almas dos fortes a nâo se perder a ilusão, hè

Na sombra do otário que se esconde o mané, hè

$\mathrm{Na}$ hora que o bicho pega que a gente vê qual è que è

evite atrazalado, tem pangarè que não vale um prato

Aquì è lobo do mato, tem xerife assustado com o cavaleiro solitário

Abre-ti sésamo, mim não gosta de cara pálida

acham que sabem tudo mas na verdade não sabem nada

Controlam as doenças, controlam dinheiro,

Controlam cartéis, controlam os puteiros

Modificam o ar, criam cérebros atômicos

È o pai de família na porta do bar, enquanto o filho está matando

Sugam da terra injetam no próprio homem

Alteram a natureza, Óleo no mar, fogo no monge

Jardins do éden, as flores tem cheiro de morte

Olhe o seu próprio COQUETEL MOLOTOV!

(repare no cara puxando a fumaça depois de falar coquetel molotov) 


\section{Anexo 2:}

\section{Zumbi}

\section{Jorge Ben Jor}

Angola Congo Benguela

Monjolo Cabinda Mina

Quiloa Rebolo

Aqui onde estão os homens

Há um grande leilão

Dizem que nele há

Um princesa à venda

Que veio junto com seus súditos

Acorrentados num carro de boi

Eu quero ver

Eu quero ver

Eu quero ver

Angola Congo Benguela

Monjolo Cabinda Mina

Quiloa Rebolo

Aqui onde estão os homens

Dum lado cana de açúcar

Do outro lado o cafezal

Ao centro senhores sentados

Vendo a colheita do algodão tão branco

Sendo colhidos por mãos negras

Eu quero ver

Eu quero ver

Eu quero ver

Quando Zumbi chegar

O que vai acontecer

Zumbi é senhor das guerras

È senhor das demandas

Quando Zumbi chega e Zumbi

É quem manda

Eu quero ver

Eu quero ver

Eu quero ver

\section{Anexo 3}

Canto Das Três Raças

Clara Nunes

Ninguém ouviu

Um soluçar de dor

No canto do Brasil

Um lamento triste

Sempre ecoou

Desde que o índio guerreiro 
Foi pro cativeiro

E de lá cantou

Negro entoou

Um canto de revolta pelos ares

No Quilombo dos Palmares

Onde se refugiou

Fora a luta dos Inconfidentes

Pela quebra das correntes

Nada adiantou

E de guerra em paz

De paz em guerra

Todo o povo dessa terra

Quando pode cantar

Canta de dor

ô, ô, ô, ô, ô, ô

ô, ô, ô, ô, ô, ô

ô, ô, ô, ô, ô, ô

ô, ô, ô, ô, ô, ô

E ecoa noite e dia

É ensurdecedor

$\mathrm{Ai}$, mas que agonia

O canto do trabalhador

Esse canto que devia

Ser um canto de alegria

Soa apenas

Como um soluçar de dor 